\title{
Kontrol Pipet Otomatis Dalam Pengambilan Sampel Plasma Darah Dengan Metode Fuzzy
}

\author{
(Automatic Pipette Control In Taking Of Blood Plasma Sample Using Fuzzy Method)
}

\author{
Ahmad Rofii, Khairul Anam*), Widya Cahyadi \\ Program Studi Teknik Elektro, Fakultas Teknik, Universitas Jember \\ J1. Kalimantan 37 Jember 68121 \\ ${ }^{*}$ Penulis Korespondensi E-mail: khairul@unej.ac.id
}

\begin{abstract}
Abstrak
Perkembangan teknologi yang semakin pesat menyebabkan peralihan teknologi yang masih manual menjadi teknologi yang lebih canggih. Pada bidang kesehatan, juga diharapkan terus dikembangkan alat-alat maupun teknologi yang semakin canggih. Salah satu alat dibidang kesehatan yang saat ini masih dapat dikembangkan, yaitu pipet yang berfungsi untuk mengambil sampel berupa cairan. Pada umunya, pipet yang digunakan dibidang laboratorium kesehatan masih bersifat manual dan diharapkan banyak dikembangkan pipet otomatis yang mempercepat dan mempermudah pengambilan sampel. Pada penelitian ini dilakukan perancangan kontrol pipet otomatis menggunakan metode fuzzy untuk pengambilan sampel plasma darah. Hal ini bertujuan agar proses pengambilan sampel yang berupa plasma darah dapat dilakukan dengan cepat dan teliti. Dua metode penyimpulan fuzzy digunakan dalam penelitian ini yaitu fuzzy mamdani dan sugeno. Tahapan pertama dari penelitian ini adalah perancangan kontrol pipet otomatis. Kontrol pipet otomatis yang dihasilkan dari penelitian ini terdiri atas LDR, LED, resistor, sensor servo, mini pump, dan rangkaian LCD yang dihubungkan dengan Arduino. Tahapan selanjutnya yaitu pengujian kinerja sensor. Kinerja sensor dan alat pada sistem diketahui dengan melakukan beberapa pengujian, yaitu pengujian sensor yang berupa uji kalibrasi, akurasi, dan presisi. Hasil pengujian akurasi sensor menunjukkan rata-rata error di bawah $5 \%$ yang berarti sensor yang dirancang cukup akurat. Selain itu nilai lumen yang di uji pada tiap sensor tidak mengalami perubahan yang besar yang menunjukkan sensor pada alat presisi. Hasil pengujian alat juga menunjukkan bahwa kinerja alat yang mengunakan metode fuzzy mamdani dan fuzzy sugeno berjalan baik hal ini terlihat pada pengujian sampel yang sama diperoleh nilai input yang cenderung sama dan nilai output yang cenderung sama.
\end{abstract}

Kata Kunci: Arduino, Fuzzy Mamdani, Fuzzy Sugeno, Pipet.

\begin{abstract}
The rapid development of technology has LED to the shift of manual technology into more sophisticated technology. The sophisticated tools and technology in the medical sector are expected to be developed. One of the them is a pipette that taking sampels in the liquid form. In general, pipettes used in the medical laboratories are still manual and it is expected that many automatic pipettes will be developed. In this research, the automatic pipette control using fuzzy method for blood plasma sampling has been designed. The purpose is order to the sampling process of blood plasma can be done quickly and thoroughly. The first step of this research is the design process of automatic pipette control. The automatic pipette control produced from this study consists of LDR, LEDs, resistors, servo sensors, minipumps, and LCD circuits that connected with Arduino. The next step is testing the sensor performance. The performance of sensors and device in the system is known by performing several tests, namely calibration tests, accuracy, and precision. The result of accuracy test show that the average error is under 5\% which means that the designed sensor is quite accurate. In addition, the lumen value tested on each sensor has not undergone a major change which shows the sensor in the precision instrument. The results of the device test also show that the performance of the device using fuzzy mamdani and fuzzy sugeno methods works well, this can be seen in the same sampel test, the input and the output values tend to be the same.
\end{abstract}

Keywords: Arduino, Automatic, Fuzzy, LDR, Pipette.

\section{PENDAHULUAN}

Perkembangan teknologi yang sangat pesat serta kebutuhan dan pengetahuan masyarakat terhadap kesehatan menimbulkan tuntutan masyarakat terhadap mutu pelayanan kesehatan [1]. Salah satu pelayanan kesehatan yang mengalami perkembangan teknologi, yaitu Laboratorium Klinik. Menurut Permenker RI No.411/Menkes/Per/III/2010, Laboratorium Klinik adalah laboratorium kesehatan yang melaksanakan pelayanan pemeriksaan spesimen klinik untuk mendapatkan informasi kesehatan perorangan terutama untuk menunjang upaya diagnosa penyakit dan memulihkan kesehatan [2].

Pemeriksaan laboratorium memiliki peran yang lebih dominan, nyata dan menghasilkan data dan spesifik sehingga menghasilkan diagnosis pasti (degnitive diagnosis) [3]. Pemeriksaan laboratorium yang dilakukan untuk pemeriksaan penyaringan terhadap kelainan dalam tubuh manusia yang dapat terjadi melalui darah atau bagian tubuh lainnya [1]. Untuk mempermudah diagnosis suatu penyakit maka diperlukan alat yang memiliki teknologi uang dapat mempermudah analisa penyakit. Salah satu alat 
yang sering digunakan untuk melakukan kegiatan analisis penyakut adalah pipet. Pipet adalah alat yang digunakan untuk mengambil dan meneteskan suatucairan atau larutan dalam jumlah kecil [2].

Untuk menghasilkan diagnosa yang tepat diperlukan jaminan mutu pemeriksaan yang memperhatikan dua hal, yaitu akurasi dan presisi [1]. Berdasarkan observasi dari beberapa rumah sakit, dalam penambahan cairan untuk analisa darah masih menggunakan pipet tetes atau pipet manual [4]. Hal tersebut mengakibatkan ketidak akuratan suatu diagnosa. Contoh penggunaan pipet untuk diagnosa penyakit memlui darah. Memindahkan cairan menggunakan pipet membutuhkan ketelitian dan waktu yang cukup lama. Contohnya pada pengambilan cairan plasma darah yang antara plasma darah dan sel darah merah sudah dipisahkan sebelumnya dengan menggunakan alat cetrifuge. Dalam hal ini, plasma darah berada diatas sel darah merah yang dibatasi dengan sel darah putih. Untuk mengambil plasma darah tersebut membutuhkan ketelitian agar sel darah merah tidak ikut terambil oleh pipet. Sehingga, membutuhkan waktu yang lama dalam proses pengambilan sampel plasma darah tersebut yang nantinya digunakan untuk diagnosa penyakit pasien.

Kontrol berbasis AI (Artifical Intelegent) menjadikan alat dapat berfikir, menimbang tindakan yang akan diambil, dan mampu mengambil keputusan, seperti yang dilakukan manusia [5]. Salah satu AI yang populer digunakan adalah logika fuzzy karena memiliki perhitungan matematis yang sederhana. Metode fuzzy digunakan untuk menentukan banyak sedikitnya tetepan pipet yang dikeluarkan. Metode fuzzy yang populer digunakan oleh para peneliti ada dua, yaitu mamdani dan sugeno sebagai perbandingan.

Oleh karena itu, diperlukan pipet yang dapat mengambil sampel plasma darah sesuai dengan yang diinginkan petugas laboratorium untuk mempermudah pekerjaannya dengan cepat dan tepat. Pada artikel ini penulis menjelaskan tentang "Kontrol Pipet Otomatis dalam Pengambilan sampel Plasma Darah dengan Metode Fuzzy"

\section{METODE PENELITIAN}

Pada artikel ini menggunakan komponen utama alat pengambil sampel plasma darah yang terdiri dari : tabung sampel plasma darah, Arduino, sensor LDR, LED dan box control. Gambar 1 merupakan diagram blok keseluruhan sistem yang digunakan. Control box pada Gambar 2 terdapat beberapa komponen utama, yaitu Arduino, servo, dan LCD.

Arduino berfungsi sebagai mikrokontroler atau pengendali seluruh komponen menjadi sebuah sistem dengan input berupa sensor LDR untuk mengukur intensitas cahaya yang diterima dari sampel berupa plasma darah didalam tabung. Kemudian input tersebut akan diproses oleh Ardino dengan menggunakan metode fuzzy. Output fuzzy berupa konstanta yang akan menentukan gerakan servo. Servo berfungsi sebagai aktuator yang digunakan untuk meneteskan jumlah cairan sampel yang dikeluarkan dari pipet.

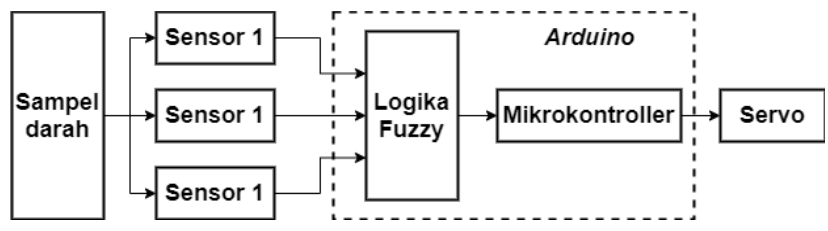

Gambar 1. Diagram Blok

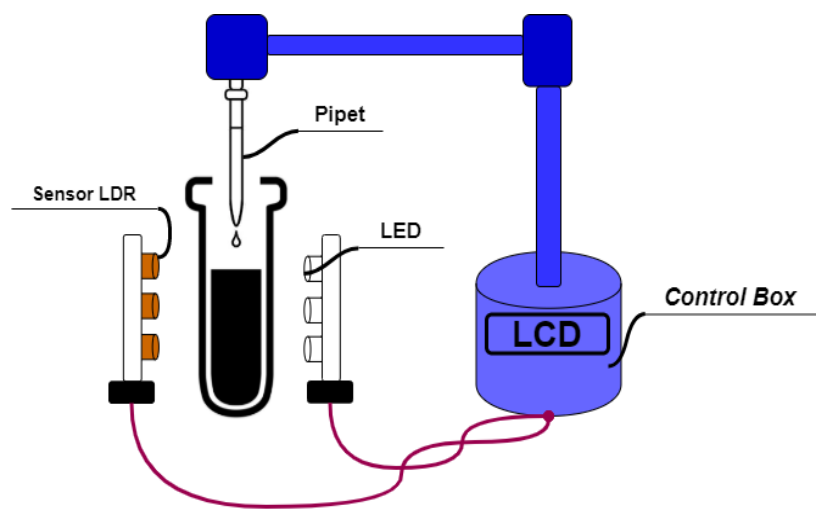

Gambar 2. Desain Alat

\section{A. Logika Fuzzy}

Logika Fuzzy merupakan salah satu cabang dari sistem AI yang memiliki nilai kekaburan atau kesamaran antara benar atau salah [6]. Sistem fuzzy terdiri dari empat komponen, yaitu rule base, mesin inferensi fuzzy (himpunan fuzzy), pembuat fuzzy (fuzzifier), dan penegasan (defuzzifier) [7]. Secara umum para peneliti menggunakan jenis metode mamdani dan metode sugeno.

\section{Himpunan Fuzzy}

Himpunan fuzzy (crips) atau nilai keanggotaan suatu input $(x)$ dalam suatu himpunan $\mathrm{A}$, yang dinyatakan dalam fungsi $\mu \mathrm{A}[x]$. Nilai fungsi $\mu \mathrm{A}[x]$ memiliki dua kemungkinan, yaitu 1 dan 0 [6]. Suatu himpunan secara umum direpresentasikan ke dalam tiga bentuk kurva, yaitu linear, segitiga, dan bentuk bahu. Pada artikel ini himpunan fuzzy input dan output menggunakan representasi kurva segitiga dan bahu, seperti pada Gambar 3 dan 4.

Pada artikel ini nilai input diperoleh dari hasil pembacaan sensor LDR berupa nilai tegangan (V), menggunakan. Tabel 1 merupakan parameter input dari representasi nilai tegangan sensor LDR. Tabel 2 merupakan parameter output yang menentukan sudut ( $\theta$ ) yang dilakukan oleh servo. Pada artikel ini menggunakan dua metode fuzzy, yaitu mamdani dan sugeno yang direpresentasikan pada Gambar 4 dan 5.

Tabel 1. Parameter input

\begin{tabular}{cc}
\hline Parameter & Nilai Tegangan $\left(\boldsymbol{x}_{\boldsymbol{i}}\right)$ \\
\hline Terang $(\mathrm{T})$ & $<2.5 \mathrm{~V}$ \\
Sedang $(\mathrm{Sd})$ & $1.5-3.5 \mathrm{~V}$ \\
Gelap $(\mathrm{G})$ & $>2.5 \mathrm{~V}$ \\
\hline
\end{tabular}


Tabel 2. Parameter input

\begin{tabular}{cc}
\hline Parameter & Sudut (ө) \\
\hline Sangat Kecil (SK) & $0-30$ \\
Kecil (K) & $25-60$ \\
Sedang (S) & $55-120$ \\
Besar (B) & $100-150$ \\
\hline
\end{tabular}

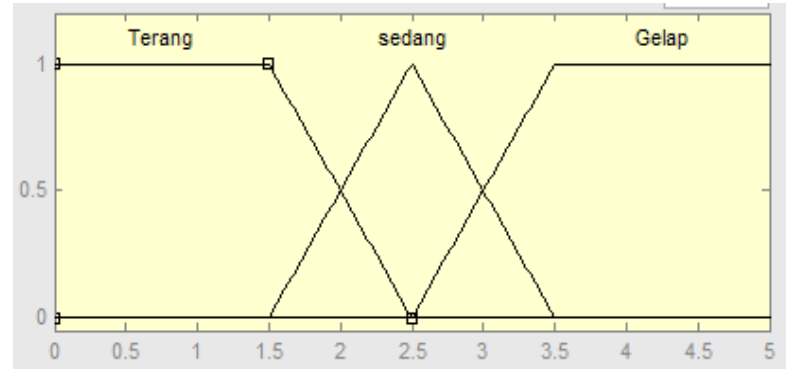

Gambar 3. Representasi Input

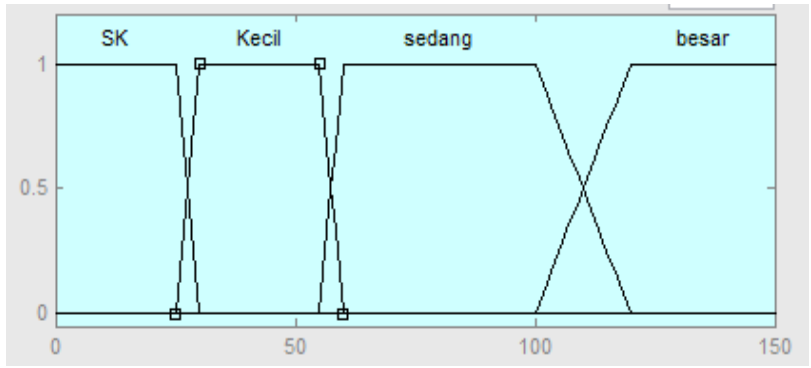

Gambar 4. Representasi output Metode Mamdani

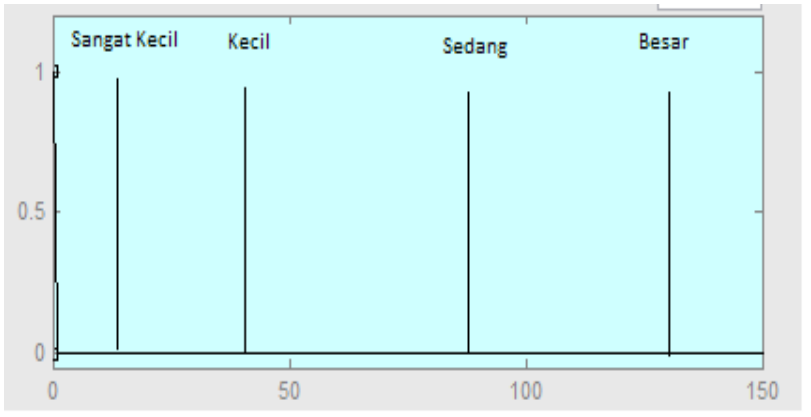

Gambar 5. Representasi Variabel Fuzzy Sugeno output

Representasi kurva input dinyatakan dalam bentuk persamaan matematis, sebagai berikut :

$$
\begin{gathered}
\mu \mathrm{T}[x]=\left(\begin{array}{c}
1 ; x \leq 0 \\
1 ; 0 \leq x \leq 1.5 \\
\frac{2.5-x}{1} ; 1.5 \leq x \leq 2.5
\end{array}\right) \\
\mu S d[x]=\left(\begin{array}{c}
0 ; x<1.5 \\
\frac{x-1.5}{1} ; 1.5 \leq x \leq 2.5 \\
\frac{2.5-x}{1} ; 2.5 \leq x \leq 3.5
\end{array}\right)
\end{gathered}
$$

$$
\mu G[x]=\left(\begin{array}{c}
0 ; x<1.5 \\
\frac{x-2.5}{1} ; 2.5 \leq x \leq 3.5 \\
1 ; 3.5 \leq x \leq 5
\end{array}\right)
$$

Representasi kurva output menggunakan metode mamdani dinyatakan dalam bentuk persamaan matematis, sebagai berikut :

$$
\begin{aligned}
& \mu \mathrm{SK}[x]=\left(\begin{array}{c}
1 ; x \leq 0 \\
1 ; 0 \leq x \leq 25 \\
\frac{30-x}{5} ; 25 \leq x \leq 30
\end{array}\right) \\
& \mu K[x]=\left|\begin{array}{c}
0 ; x \leq 25 \text { ata } x \geq 60 \\
\frac{x-25}{5} ; 25 \leq x \leq 30 \\
1 ; 30 \leq x \leq 55 \\
\frac{50-x}{50} ; 55 \leq x \leq 60
\end{array}\right| \\
& \mu \mathrm{S}[x]=\left|\begin{array}{c}
0 ; x \leq 55 \text { at au } x \geq 120 \\
\frac{x-55}{5} ; 55 \leq x \leq 60 \\
1 ; 30 \leq x \leq 100 \\
\frac{100-x}{10} ; 100 \leq x \leq 120
\end{array}\right| \\
& \mu B[x]=\left(\begin{array}{c}
0 ; x \leq 100 \text { atau } x \geq 150 \\
\frac{x-100}{10} ; 100 \leq x \leq 120 \\
1 ; 120 \leq x \leq 150
\end{array}\right)
\end{aligned}
$$

\section{Rule Base}

Rule base atau FIS (Fuzzy Inferense Engine) merupakan sebuah aturan dasar fuzzy atau sistem yang dapat melakukan penalaran dengan untuk menetapkan hubungan nilai keanggotaan input dan output [6], [8]. Secara umum FIS menggunakan penalasan IF-THEN. FIS dengan menggunakan metode mamdani menggunakan fungsi min dengan cara mengambil nilai minimum aturan, seperti pada persamaan berikut :

$$
\mu A[x]=\min \left(\mu A\left[x_{i}\right], \mu k\left[x_{i}\right]\right)
$$

dimana $\mu \mathrm{A}[\mathrm{x}]$ merupakan fungsi keanggotaan solusi fuzzy sampai aturan ke-i dan $\mu \mathrm{k}[\mathrm{x}]$ adalah nilai keanggotaan konsekuen fuzzy aturan ke-i.

FIS dengan menggunakan metode sugeno menggunakan model orde-nol yang secara umum menggunakan model matematis dengan persamaan, sebagai berikut:

$$
\text { I } F\left(x_{1} \text { is } A_{1}\right) \circ \ldots \circ\left(x_{i} \text { is } A_{i}\right) T H E N z=p_{1} * x_{1}+\ldots+p_{i} * x_{i}
$$

dimana $A_{i}$ adalah himpunan fuzzy ke- $i$ sebagai anteseden, $z$ adalah output dan $p_{i}$ adalah konstanta tegas ke- $i$. 
Tabel 3. Rule base sistem fuzzy

\begin{tabular}{cccc}
\hline & Input $\left(\boldsymbol{x}_{\boldsymbol{i}}\right)$ & & \\
\cline { 1 - 3 } $\boldsymbol{x}_{\boldsymbol{1}}$ & $\boldsymbol{x}_{\boldsymbol{2}}$ & $\boldsymbol{x}_{\boldsymbol{3}}$ & output $\boldsymbol{( \boldsymbol { \theta } )}$ \\
\cline { 1 - 2 } Terang & Terang & Terang & Besar \\
Terang & Terang & Sedang & Besar \\
Terang & Terang & Gelap & Sedang \\
Terang & Sedang & Terang & Sedang \\
Terang & Sedang & Sedang & Kecil \\
Terang & Sedang & Gelap & Kecil \\
Terang & Gelap & Terang & Sangat kecil \\
Terang & Gelap & Sedang & Sangat kecil \\
Terang & Gelap & Gelap & Sangat kecil \\
Sedang & Terang & Terang & Sangat kecil \\
Sedang & Terang & Sedang & Sangat kecil \\
Sedang & Terang & Gelap & Sangat kecil \\
Sedang & Sedang & Terang & Sangat kecil \\
Sedang & Sedang & Sedang & Sangat kecil \\
Sedang & Sedang & Gelap & Sangat kecil \\
Sedang & Gelap & Terang & Sangat kecil \\
Sedang & Gelap & Sedang & Sangat kecil \\
Sedang & Gelap & Gelap & Sangat kecil \\
Gelap & Terang & Terang & Sangat kecil \\
Gelap & Terang & Sedang & Sangat kecil \\
Gelap & Terang & Gelap & Sangat kecil \\
Gelap & Sedang & Terang & Sangat kecil \\
Gelap & Sedang & Sedang & Sangat kecil \\
Gelap & Sedang & Gelap & Sangat kecil \\
Gelap & Gelap & Terang & Sangat kecil \\
Gelap & Gelap & Sedang & Sangat kecil \\
Gelap & Gelap & Gelap & Sangat kecil \\
\hline Selann & & &
\end{tabular}

3. Defuzzifikasi

Defuzzifikasi atu penegasan memiliki input berupa suatu himpunan fuzzy yang diperoleh dari komposisi aturanaturan fuzzy. Sedangkan, output yang dihasilkan merupakan suatu bilangan dominan himpunan fuzzy tersebut [9]. Penegasan yang digunakan menggunakan metode Centeroid dengan persamaan, sebagai berikut:

$$
z^{O}=\frac{\sum_{j=1}^{i} z \mu_{1}\left(Z_{i}\right)}{\sum_{j=1}^{i} \mu\left(Z_{i}\right)}
$$

dimana $\mathrm{z}^{\circ}$ adalah nilai output penegasan yang digunakan untuk menentukan pergerakan sudut $(\theta)$ servo.

\section{B. Flowchart Sistem}

Pada artikel ini alat kontrol pipet otomatis menggunakan logika fuzzy memerlukan tahapan keseluruhan, seperti pada Gambar 6.

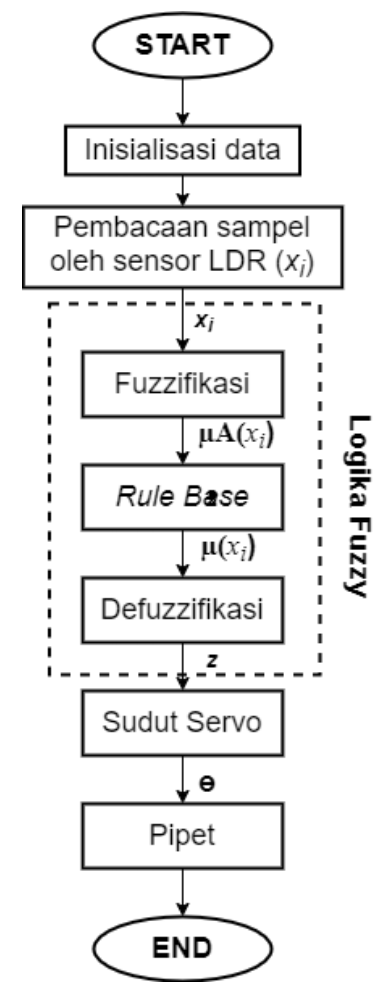

Gambar 6. Flowchart Sistem

Dalam pembuatan kontrol pipet otomatis menggunakan metode logika fuzzy mempunyai diagram alur sistem sebagai acuan, seperti pada Gambar 6.

Gambar 6 merupakan flowchart sistem keseluruhan dari kontrol pipet otomatis menggunakan metode fuzzy. Input merpakan hasil pembacaan sensor LDR $\left(x_{i}\right)$ sebanyak 3buah yang digunakan untuk membaca intensitas cahaya yang diterima oleh sensor dari LED yang melewati sampel, yaitu plasma darah.

Kemudian input diproses menggunakan metode logika fuzzy, yaitu metode mamdani dan sugeno sebagai perbandingan. Nilai dari input yang diterima menentukan nilai output yang digunakan untuk menentukan besar sudut servo saaat bergerak. Semakin besar sudut servo maka semakin banyak cairan sampel yang diambil atau dikeluarkan oleh pipet.

\section{HASIL DAN PEMBAHASAN}

\section{A. Pengujian Sensor}

\section{Kalibrasi Sensor}

Pada artikel ini sistem kalibrasi dilakukan dengan membandingkan hasil pengukuran sensor LDR dengan hasil ukur yang sudah di kalibrasi yaitu Lux-Meter untuk mendapatkan perbandingan nilai sensor yang akurat dalam satuan lumen $(\mathrm{lm})$. Hasil pembacaan LDR berupa tegangan yang berbeda-beda sesuai dengan intensitas cahaya yang diujikan yang dibandingkan dengan hasil pembacaan dari Lux-Meter, seperti pada Tabel 4. Sehingga, didapatkan suatu persamaan linear hubungan antara tegangan LDR dengan nilai intensitas cahaya dari Lux-Meter. Persamaan linear tersebut digunakan untuk mengkonversi hasil pembacaan LDR dari tagangan (V) menjadi satuan lumen 
(lm), seperti pada Gambar 7. Berdasarkan Gambar 7 didapatkan suatu persamaan, sebagai berikut :

$$
f(x)=-4.86 x+4493.87
$$

Tabel 4. Hasil Kalibrasi

\begin{tabular}{ccc}
\hline LDR $(\boldsymbol{x})$ & ADC & Lux-Meter (lm) \\
\hline 4,44 & 910 & 254 \\
4,39 & 898 & 234 \\
3,41 & 697 & 853 \\
3,27 & 671 & 928 \\
2,64 & 541 & 2101 \\
2,16 & 442 & 1949 \\
1,94 & 398 & 2782 \\
1.22 & 251 & 3450 \\
0,31 & 134 & 3850 \\
0,18 & 37 & 4220 \\
\hline
\end{tabular}

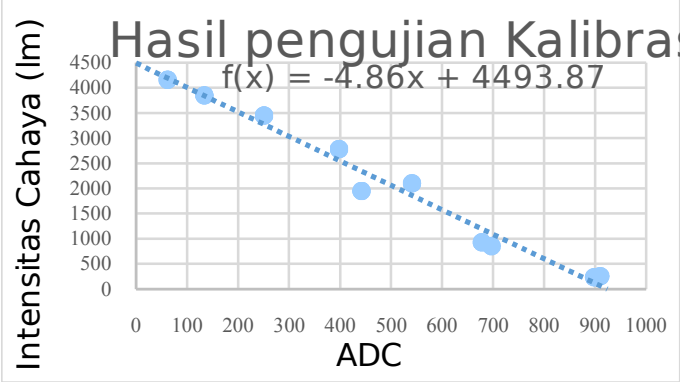

Gambar 7. Grafik Linier Kalibrasi

Tabel 5. Hasil Pengujian Akurasi Sensor LDR

\begin{tabular}{ccc}
\hline $\boldsymbol{x}(\mathbf{l m})$ & Lux-Meter $(\mathbf{l m})$ & error $(\%)$ \\
\hline 4193 & 4321 & 3 \\
3974 & 3801 & 4 \\
3653 & 3254 & 3,6 \\
301 & 335 & 11.3 \\
256 & 244 & 4.6 \\
\multicolumn{2}{c}{ error rata-rata $(\%)$} & 5.3 \\
\hline
\end{tabular}

Tabel 6. Hasil Pengujian Nilai Presisi LDR $\left(x_{i}\right)$

\begin{tabular}{ccc}
\hline $\boldsymbol{x}_{\boldsymbol{1}}(\mathbf{l m})$ & $\boldsymbol{x}_{\boldsymbol{2}}(\mathbf{l m})$ & $\boldsymbol{x}_{3}(\mathbf{l m})$ \\
\hline 4190 & 2492 & 290 \\
4057 & 2477 & 280 \\
4223 & 2514 & 293 \\
4156 & 2503 & 287 \\
4186 & 2497 & 291 \\
\hline
\end{tabular}

Tabel 7. Hasil Pengujian Fuzzy Mamdani

\begin{tabular}{cccccc}
\hline \multicolumn{3}{c}{ Input (x) } & $\begin{array}{c}\text { output } \\
(\boldsymbol{\theta})\end{array}$ & $\begin{array}{c}\text { Waktu } \\
(\mathbf{s})\end{array}$ & $\begin{array}{c}\text { Jarak } \\
\text { sampel } \\
(\mathbf{c m})\end{array}$ \\
\hline $\boldsymbol{x}_{\boldsymbol{1}}$ & $\boldsymbol{x}_{\mathbf{2}}$ & $\boldsymbol{x}_{\mathbf{3}}$ & & & 2,7 \\
0,8 & 1,9 & 4,68 & 39,20 & 29,0 & 2,7 \\
0,94 & 2,48 & 4,78 & 63,97 & 28,2 & 2,2 \\
1,22 & 3,73 & 4,80 & 64,99 & 28 & 2,16 \\
2,05 & 4,42 & 4,77 & 86,80 & 27,9 & 1,8 \\
3,05 & 3,50 & 4,83 & 128,79 & 26 & 0,9 \\
\hline
\end{tabular}

Tabel 4 terlihat bahwa nilai ADC berbanding terbalik dengan nilai lumen, yaitu semakin besar nilai ADC maka semakin kecil nilai lumen. Besar nilai lumen di pengaruhi oleh intensitas cahaya, sehingga semakin besar intensitas cahaya maka nilai lumen juga besar. Intensitas cahaya juga berpengaruh pada nilai ADC pada LDR. Semakin besar intensitas cahaya maka nilai resistansi pada LDR semakin meningkat sehingga tegangan pada LDR semakin besar.

\section{Akurasi Sensor}

Pada artikel ini, pengujian akurasi dilakukan sebanyak 5 kali percobaan dengan 5 sampel yang berbeda. Kemudian setiap sampel dibandingkan nilai lumen yang terbaca dari sensor LDR dan nilai lumen pada Lux-Meter. Pengujian akurasi sensor digunakan untuk mengetahui perbandingan nilai pada sensor yang sudah di kalibrasi dan nilai Lux meter sehingga bisa diketahui berapa persen nilai error pada LDR, seperti pada Tabel 5. Pada hasil pengujian akurasi sensor dapat dilihat rata-rata error pada 5 pengujian menunjukan nilai error dibawah $10 \%$ sehingga dapat disimpulkan akurasi sensor dikatakan akurat.

\section{Presisi Sensor}

Pengujian presisi sensor bertujuan untuk mengetahui perubahan nilai lumen pada tiap sensor. Pengujian dilakukan terhadap 3-LDR $\left(\mathrm{x}_{\mathrm{i}}\right)$ dengan besar intensitas yang berbeda disetiap sensor yang diuji sebanyak 5 kali percobaan. Hasil pengujian dapat dilihat pada Tabel 6. Dari Tabel 6 menunjukkan bahwa nilai lumen yang di uji pada tiap sensor tidak mengalami perubahan yang besar dan dapat disimpulkan sbahwa sensor pada alat presisi.

\section{B. Pengujian Fuzzy}

\section{Metode Mamdani}

Pada pengujian alat dengan metode mamdani dengan melakukan pengujian mengunakan 5 sampel darah yang sudah terpisah antara sel darah merah dan plasma darah. Dimana setiapn sensor dapat membaca tingkat intensitas cahaya yang menembus sampel, sehingga, intensitas cahaya yang diterima sensor bisa berbeda. Kemudian nilai sensor digunakan sebagai input $(x)$ pada metode mamdani yang menentukan output berupa sudut gerakan servo. Tabel 7 merupa kan hasil pengujian alat dengan menggunakan metode mamdani. Dari hasil pengujian alat dengan metode fuzzy mamdani yang dapat dilihat pada Tabel 7, diketahui 
bahwa ketinggian sampel mempengaruhi pembacaan sensor terhadap cahaya yang terhalangi oleh sampel.

\section{Metode Sugeno}

Pada pengujian alat dengan metode fuzzy sugeno pengujian dilakukan dengan mengunakan 5 sampel darah yang sudah terpisah antara sel darah merah dan plasma darah dan tiap sensor membaca besar intensitas cahaya yang menembus sampel, dan intensitas cahaya yang diterima sensor bisa berbeda. Nilai 3 sensor tersebut selanjutnya digunakan untuk menentukan output berupa sudut dari pergerakan servo. Hasil pengujian alat dengan metode fuzzy sugeno bisa di lihat pada Tabel 8 .

Tabel 8. Hasil Pengujian Fuzzy Sugeno

\begin{tabular}{|c|c|c|c|c|c|}
\hline \multicolumn{3}{|c|}{ Input $\left(x_{i}\right)$} & \multirow{2}{*}{$\begin{array}{c}\text { Output } \\
(\boldsymbol{\theta})\end{array}$} & \multirow{2}{*}{$\begin{array}{c}\text { Waktu } \\
\text { (S) }\end{array}$} & \multirow{2}{*}{$\begin{array}{r}\text { Jarak } \\
(\mathrm{cm})\end{array}$} \\
\hline$x_{1}$ & $x_{2}$ & $x_{3}$ & & & \\
\hline 0,84 & 1,97 & 4,71 & 43,58 & 28,8 & 2,6 \\
\hline 0,95 & 2,46 & 4,77 & 64,99 & 28,3 & 2,16 \\
\hline 1,45 & 3,75 & 4,82 & 64,99 & 28 & 2,16 \\
\hline 2,03 & 4,48 & 4,84 & 84,99 & 27,6 & 1,75 \\
\hline 3,12 & 3,68 & 4,85 & 126,40 & 27 & 0,9 \\
\hline
\end{tabular}

\section{KESIMPULAN}

Pada artikel ini yang telah dibahas tentang kontrol pipet otomatis berbasis fuzzy menggunakan sensor LDR untuk mengetahui intensitas cahaya dari sampel sebagai input untuk menentukan gerakan sudut servo sebagai output. Sehingga menghasilkan suatu sistem kontrol pipet otomatis yang dapat mengambil atau meneteskan cairan sesuai dengan yang parameter yang diinginkan.

Pada artikel ini menggunakan sensor LDR yang telah dikalibrasi dengan Lux-Meter untuk mendeteksi intensitas cahaya dalam satuan lumen memiliki tingkat error sebesar 5.3\%. Sensor LDR digunakan untuk mengetahui perubahan intensitas cahaya yang diterima dari sampel berupa plasma darah. Artikel ini menggunakan dua jenis kontrol metode fuzzy, yaitu mamdani dan sugeno yang dibandingkan. Berdasarakan percobaan yang telah dilakukan diketahui bahwa nilai input yang diuji kan memiliki nilai yang cenderung sama sehingga nilai output memiliki nilai yang cendeung rsama. Namun, dalam implementasi kedua metode tersebut metode sugeno lebih sederhana secara matematis.

\section{SARAN}

Hal-hal yang dapat disarankan untuk kegiatan penelitian berikutnya yang berhubungan dengan "Kontrol Pipet Otomatis Dalam Pengambilan sampel Plasma Dengan Metode Fuzzy" adalah perlu adanya penelitian lebih lanjut dengan alat yang sama tetapi dengan metode yang berbeda untuk mengetahui dengan metode berbeda alat menjadi lebih baik kinerjanya atau justru sebaliknya dan dapat diketahui pula metode mana yang lebih baik.

\section{DAFTAR PUSTAKA}

[1] Hdayatussalihin, E. Nurhayati, and E. Suwandi, "Perbedaan Presisi Pemipetan Sampel Menggunakan Pipet Sahli Dan Mikropipet Pada Pemeriksaan Hemoglobin Metode Cyanmethemoglobin," J. Lab. Khatulistiwa, vol. 2, no. 2, pp. 21-25, 2018.

[2] Mardiana and I. G. Rahayu, Pengantar Laboratorium Medik. 2017.

[3] T. W. Sardjono, G. Ismanoe, and E. Widjayanto, "Peran Laboratorium dalam Diagnosis dan Penatalaksanaan Kasus-Kasus Penyakit Tropik dan Infeksi," J. Kedokt. Brawijaya, vol. XX, no. 1, pp. 19 24, 2004.

[4] I. Wahyudi, H. . Muslim, and M. Nazarudin, "Perbedaan Jumlah Trombosit Dengan Penggunaan Pipet Tetes dan Mikropipet dalam Penambahan Antikoagulan," J. ERGASTERIO, vol. 04, no. 01, pp. 41-47, 2017.

[5] J. Nasir and J. Suprianto, “Analisis Fuzzy Logic Menentukan Pemilihan Motor Honda Dengan Metode Mamdani," J. Edik Inform., vol. 3, no. 2, pp. 177-186, 2017.

[6] S. Komariyah, R. M. Yunus, and S. F. Rodiyansyah, "Metode Logika Fuzzy Dalam Sistem Pengambilan Keputusan Penerimaan Beasiswa," Semin. Teknol. Majalengka2, pp. 61-68, 2016.

[7] S. Batubara, "Analisis Perbandingan Metode Fuzzy Mamdani Dan Fuzzy Sugeno Untuk Penentuan Kualitas Cor Beton Instan," It J. Res. Dev. J. Res. Dev., vol. 2, no. 1, pp. 1-11, 2017.

[8] A. H. Agustin, G. . Ghandhiadi, and T. B. Oka, "Penerapan Metode Fuzzy Sugeno Untuk Menentukan Harga Jual Sepeda Motor Bekas," E-Jurnal Mat., vol. 5, no. 4, pp. 176-182, 2016.

[9] A. G. Salman, "Pemodelan Dasar Sistem Fuzzy," School of Computer Science Universitas BINUS. [Online].

Available: https://socs.binus.ac.id/2012/03/02/pemodelan-dasarsistem-fuzzy/. [Accessed: 04-Mar-2020]. 